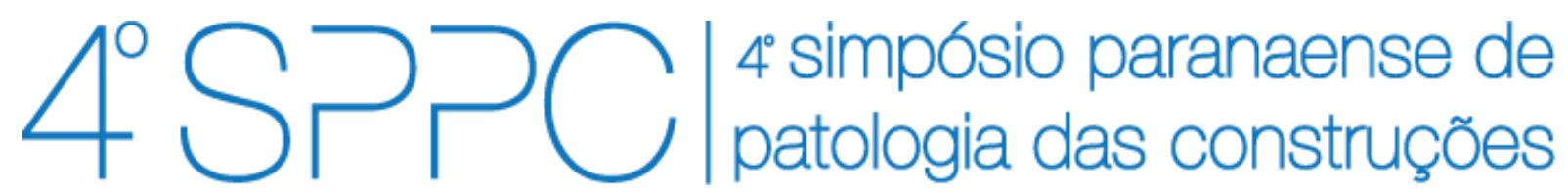

ISSN 2526-7248 artigo n. 4SPPC112, pp. 91-100, 2019

\title{
Diagnóstico de manifestações patológicas para recuperação de ponte de concreto armado
}

\author{
Santos, Carolina. G. dos $^{1}$; Benetti, H. Piassa. ${ }^{2}$; Dias, G. Lacerda. ${ }^{3}$ \\ ${ }^{1}$ Graduanda Eng. Civil, UTFPR/PB, carolinas@alunos.utfpr.edu.br \\ ${ }^{2}$ Prof ${ }^{a}$. Dra. Eng. Civil, UTFPR/PB, hpiassa@utfpr.edu.br \\ ${ }^{3}$ Prof. Dr. Eng. Civil, UTFPR/PB, lacerda@utfpr.edu.br
}

Resumo: Encontrar técnicas para identificação das manifestações patológicas em pontes e métodos para sua recuperação é uma alternativa eficaz para que esse cenário seja modificado. Existe no Paraná um número significativo de pontes construídas desde a década de 1960, que apresentam carência de acompanhamento e manutenção periódica, propiciando o surgimento de manifestações patológicas. O objetivo do trabalho é propor técnicas para diagnóstico e recuperação de um cenário patológico em uma ponte sobre o Rio Xagú, de concreto armado e elementos metálicos, possibilitando chegar a um diagnóstico das manifestações patológicas, utilizando inspeção visual com registro fotográfico. Com o diagnóstico foi possível comprovar que a inoperância das juntas de dilatação causou o surgimento de trincas junto ao pórtico de concreto, permitindo a entrada de água na estrutura e causando outros mecanismos de degradação como lixiviação, carbonatação, corrosão das armaduras e desplacamento do concreto. A análise mostrou que as manifestações patológicas não ocorrem de maneira isolada, e para que a estrutura seja recuperada não basta reparar cada uma delas individualmente, e sim levar em consideração a origem do problema, para que a estrutura não volte a se deteriorar.

Palavras-chave: Manifestações patológicas, diagnóstico, recuperação, pontes, concreto armado.

\begin{abstract}
It is important to identify the pathological manifestations in bridges and find effective methods for its rehabilitation, in order to change that situation. In Paraná State, Brazil, there is a significant number of bridges, constructed in the 1960's, that miss a regular inspection and maintenance, and the consequence are occurrence of many of these manifestations. This paper presents the techniques used for the diagnosis and rehabilitation of a bridge over Xagú river, composed of reinforced concrete and steel elements. For this purpose, it was held a visual inspection at the bridge with photographic records. The diagnostic proves that the ineffectiveness of the expansion joints caused the emergence of cracks along the concrete frames, thus enabling the entrance of water in the structure and causing other types of degradation mechanisms, as well as leaching (lixiviation), carbonation, corrosion of armors and releasing of concrete from the structure. The results of the inspection shows that the pathologies do not appear in an isolated manner, and thus, to recover the structure, it is not worth to repair the elements individually, but considering the origins of the problem to avoid that the structure deteriorate once again.
\end{abstract}

Keywords: Pathological manifestations, diagnostic, rehabilitation, bridges, reinforced concrete. 
SANTOS, C. G. DOS; BENETTI, H. P.; DIAS, G. L.. TÉCNICAS PARA RECUPERAÇÃO DE PONTE DE CONCRETO ARMADO: ESTUDO DE CASO. $4^{\circ}$ Simpósio Paranaense de Patologia das Construções (40 SPPC), artigo 4SPPC112, pp. 91 - 100, 2019. DOI: $10.4322 / 2526-7248.032$

\section{Introdução}

Na engenharia civil, especialmente na área de execução de obras, pode-se afirmar que a principal preocupação dos profissionais converge à capacidade da estrutura em resistir aos esforços aplicados e às intempéries referentes ao local em que é construída. Porém, existe uma carência no planejamento de manutenção dessa estrutura com o passar do tempo, o que pode fazer com que haja o surgimento de sintomas não desejados, como manifestações patológicas. A premeditação da manutenção que a estrutura vai precisar ao longo dos anos é a garantia de que seu desempenho seja satisfatório também em longo prazo [1].

De acordo com [2], o termo "manifestações patológicas" pode ser usado para definir os sintomas que indicam a degradação de uma estrutura. Assim, [2] ainda afirma que "uma manifestação patológica é a expressão resultante de um mecanismo de degradação, e a patologia é uma ciência [...] que serve para explicar este mecanismo".

Estudar a origem e as consequências do surgimento de manifestações patológicas nas estruturas está profundamente ligado ao estudo de sua durabilidade, e o diagnóstico correto do tipo de manifestação existente é fundamental para que a estrutura receba o tratamento adequado. Sendo assim, é importante que os profissionais da engenharia utilizem estes conhecimentos para garantir o bom desempenho da edificação.

O aparecimento de mecanismos de degradação como trincas ou fissuras, corrosão das armaduras, deterioração do concreto, pode ocorrer em cada fase da construção, e em diferentes elementos da edificação, e para cada caso existem técnicas que podem auxiliar na caracterização dessas falhas. Neste trabalho são abordadas manifestações patológicas que podem ocorrer em estruturas de concreto armado, que apesar de ser o tipo de estrutura mais utilizado no Brasil [3], segundo Medeiros [4] ainda existe muita dificuldade em aplicar o conhecimento já consolidado, fazendo com que as estruturas de concreto armado atuais estejam mais susceptíveis à ocorrência de manifestações patológicas e mecanismos de degradação.

O foco do trabalho é analisar e caracterizar as manifestações patológicas existentes em uma ponte de concreto armado localizada no Sudoeste do Paraná sobre o Rio Xagú, no município de Rio Bonito do Iguaçu, além de propor técnicas para sua recuperação. A escolha de uma ponte se deu pela existência de um considerável número de obras de infraestrutura, na região, que foram construídas a partir da década de 1960 e hoje apresentam sintomas patológicos.

\section{Manifestações Patológicas em estruturas de concreto armado}

Em uma ponte de concreto armado, os tipos de mecanismos de degradação mais recorrentes são: corrosão de armaduras, deterioração de peitoris, degradação de juntas de dilatação, percolação de água, deterioração de apoios, fissuras e desgaste da pavimentação [5-6]. 
SANTOS, C. G. DOS; BENETTI, H. P.; DIAS, G. L.. TÉCNICAS PARA RECUPERAÇÃO DE PONTE DE CONCRETO ARMADO: ESTUDO DE CASO. $4^{\circ}$ Simpósio Paranaense de Patologia das Construções (40 SPPC), artigo 4SPPC112, pp. 91 - 100, 2019. DOI: $10.4322 / 2526-7248.032$

A corrosão das armaduras está relacionada à porosidade do concreto, que por sua vez é relativa à quantidade de água utilizada na composição do concreto. Quanto maior for a relação água/cimento, maior será a porosidade do concreto, e caso a porosidade seja maior do que a admissível, as armaduras estarão mais expostas aos agentes corrosivos. Outros fatores que devem ser levados em conta são o cobrimento mínimo de concreto, que garanta a proteção das armaduras, a resistência característica do concreto adotada no projeto, bem como o lançamento, adensamento e cura adequados do concreto. Caso não sejam levados em consideração, em pouco tempo a armadura estará desprotegida e exposta aos agentes corrosivos.

A deterioração dos guarda corpos de concreto pode se dar devido a impactos recorrentes, e ao longo do tempo, se não forem sujeitos à manutenção, podem surgir manifestações comuns a elementos de concreto.

Caso não haja impermeabilização do concreto, ou devido à presença de fissuras que permitam a passagem de água, pode ocorrer a percolação da água pelo concreto. Na construção de pontes no Brasil, as medidas mais adotadas para impedir a ocorrência deste tipo de sintoma são o controle das fissuras no tabuleiro e o desenvolvimento de materiais permeáveis [7].

Os apoios das pontes são os pilares que recebem todas as cargas da superestrutura da ponte e as transmitem às fundações, que por sua vez, transmitem as cargas ao solo resistente. A deterioração dos apoios pode evoluir com o passar do tempo e trazer sérias consequências, mas pode ser acelerada caso alguns erros tenham sido cometidos, seja na fase de projeto ou na execução da obra. Como exemplo, a escolha equivocada da classe de agressividade ambiental do local da construção da ponte, ou até mesmo o posicionamento inadequado das armaduras [5].

O surgimento de fissuras pode se dar devido ao assentamento e retração plástica, retração por secagem, assentamento dos apoios, deficiências estruturais, agregados reativos, corrosão de armaduras, restrições a alongamentos e encurtamentos térmicos e ataques de cloretos e sulfatos [6], e podem diminuir a rigidez das vigas, expor as armaduras às intempéries, além de causar danos estéticos e desconforto psicológico [8].

No manual de recuperação de pontes e viadutos rodoviários, criado pelo DNIT (2010), são citados alguns tipos de fissuras e seu local de ocorrência: 1- Fissura por excessiva exsudação, no assentamento plástico do concreto. Localização: ao longo das barras das armaduras e nas mudanças de forma das seções; 2- Fissura por evaporação rápida e cura inadequada, na fase de retração plástica do concreto. Localização: na superfície dos elementos concretados, com pouca umidade e em ambientes muito secos; 3- Fissura por armadura insuficiente ou inadequada nas juntas de construção, na fase de retração térmica inicial. Localização: perpendiculares às juntas de construção; 4- Fissura por encurtamento normal do concreto, com a perda de umidade. Localização: perpendiculares aos encurtamentos; 5- Fissura devido ao aumento de volume das armaduras decorrente da corrosão. Localização: ao longo das armaduras; 6- Fissura devido a variações de temperatura e retração residual. Localização: normais à direção dos impedimentos; 
SANTOS, C. G. DOS; BENETTI, H. P.; DIAS, G. L.. TÉCNICAS PARA RECUPERAÇÃO DE PONTE DE CONCRETO ARMADO: ESTUDO DE CASO. $4^{\circ}$ Simpósio Paranaense de Patologia das Construções (40 SPPC), artigo 4SPPC112, pp. 91 - 100, 2019. DOI: $10.4322 / 2526-7248.032$

7-Fissuras devido a cargas móveis não previstas ou dimensionamento insuficiente. Localização: nos elementos estruturais excessivamente solicitados [6].

Os defeitos na pavimentação da ponte são facilmente identificados visualmente, que podem ser deformações na massa asfáltica, trincas, formação de panelas (Fig. 3), e pontos de degradação nas juntas de dilatação da estrutura. O desgaste na pavimentação da ponte pode pôr em risco a segurança e o conforto dos usuários que trafegam pelas vias [9].

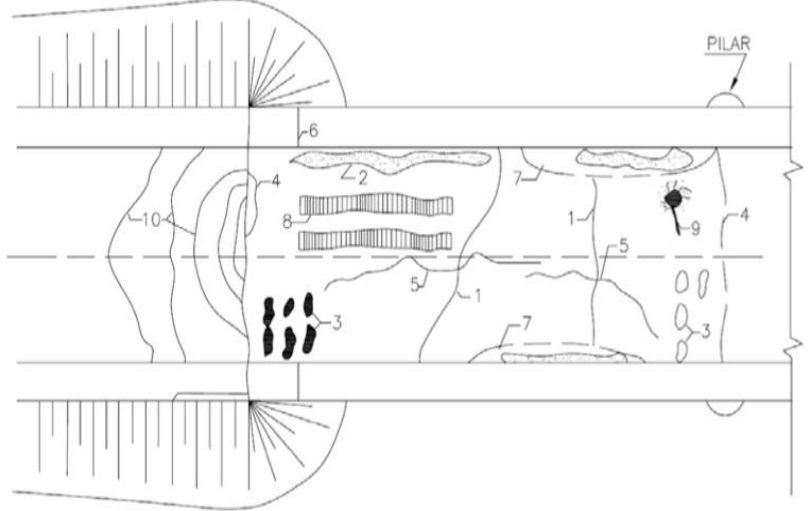

$\begin{array}{lrr}\text { 1- Trincas transversais; } & 2- \\ \text { Contaminação junto às barreiras; } & 3- \\ \text { Falhas e defeitos; 4-Trincas junto às } \\ \text { juntas de dilatação; } & \text { 5-Trincas } \\ \text { longitudinais; } & \text { 6-deterioraçao } & \text { e } \\ \text { vazamentos junto às barreiras; } & 7- \\ \text { Deformaçao do pavimento; } & 8- \\ \text { Deformaçao do pavimento, na forma de } \\ \text { impressões das rodas; 9-Deterioraçao } \\ \text { do pavimento, resultante da fraqueza do } \\ \text { material; 10-Rugosidades do pavimento } \\ \text { nas regiões de transição aterro-ponte, } \\ \text { por falta de laje de transição e por } \\ \text { assentamento do aterro de acesso. }\end{array}$

Figura 1: Mecanismos de degradação de causas físicas na pavimentação [6].

\subsection{Técnicas para diagnóstico da estrutura}

Para identificar visualmente as manifestações patológicas presentes na ponte, Ferreira [10] cita que é necessário analisar detalhadamente os elementos da ponte como juntas, aparelhos de apoio, sistemas de drenagem, guarda-corpos, pavimentação e revestimentos, e durante o exame visual, é preciso registrar, quantificar, dimensionar e localizar as manifestações patológicas e falhas observadas nos elementos da estrutura.

Para chegar ao diagnóstico correto, é preciso levar em consideração os fatores particulares de cada estrutura, e entender que mesmo seguindo, de maneira geral um roteiro para identificar as manifestações patológicas, nenhuma ponte é igual à outra, e os fatores externos precisam ser considerados [11], como a quantidade de nível de detalhamento de dados a serem levantados, recursos e equipamentos disponíveis para o acesso e ensaio à estrutura, prazo de execução e a qualificação da equipe que irá realizar a inspeção.

\subsection{Técnicas para recuperação da estrutura}

Segundo Souza e Ripper [1], "[...] o estudo e entendimento das causas, depois do problema patológico instalado, são elementos da maior importância para que a cura da estrutura seja efetivamente alcançada, pois o sucesso e a durabilidade da intervenção dependerão da escolha do método apropriado de combate ao mesmo [...]". Após a elaboração do plano geral de recuperação da estrutura, é preciso analisar cada sintoma de maneira particular, pois para cada manifestação patológica existem técnicas consolidadas para sua recuperação. Algumas citadas são: 
SANTOS, C. G. DOS; BENETTI, H. P.; DIAS, G. L.. TÉCNICAS PARA RECUPERAÇÃO DE PONTE DE CONCRETO ARMADO: ESTUDO DE CASO. $4^{\circ}$ Simpósio Paranaense de Patologia das Construções (40 SPPC), artigo 4SPPC112, pp. 91 - 100, 2019. DOI: $10.4322 / 2526-7248.032$

remoção de concreto, substituição de concreto, remoção de corrosão, remoção de manchas, tratamentos de vazios e desagregações, tratamento de trincas e fissuras (ativas ou inativas) [6].

Antes de iniciar um processo de recuperação de uma estrutura, a partir do plano de recuperação, deve ser feita a análise se a recuperação da estrutura é a solução mais viável economicamente, pois a estrutura pode estar danificada em um nível muito avançado, onde a melhor solução seja a demolição, e possivelmente a construção de uma nova obra para substituição, ou até mesmo a não intervenção, quando o propósito funcional da estrutura estiver ultrapassado [5].

\section{Metodologia}

A primeira etapa para realização deste trabalho partiu de uma revisão bibliográfica referente às áreas de estudo de interesse. O tema inicial escolhido para este trabalho partiu da análise do comportamento de estruturas, com foco em manifestações patológicas, e a partir desta definição foi possível a identificação dos mecanismos de degradação.

As próximas etapas consistiram na escolha de uma ponte para análise patológica e a coleta de dados no local através de fotografias e documentação. Além disso, partindo ainda da revisão bibliográfica, foi possível a identificação dos diferentes tipos e origens das manifestações patológicas que podem surgir em uma ponte de concreto armado, além da identificação de técnicas de diagnóstico e recuperação para este tipo de estrutura. Por fim, levando em consideração as condições de acesso à estrutura, foi possível aplicar essas técnicas na ponte selecionada, e elaborar as considerações finais analisando os resultados obtidos.

\section{Resultados e discussões}

A ponte sobre o Rio Xagú, que está localizada no quilômetro 421, da BR-158, entre os municípios de Saudade do Iguaçu e Rio Bonito do Iguaçu, possui 95 metros de comprimento e 9,80 metros de largura. Sua estrutura pode ser classificada como mista, pois é composta por concreto armado e elementos metálicos.

Inicialmente, serão apresentadas as manifestações patológicas encontradas na superestrutura e mesoestrutura da referida ponte, a qual é composta por cinco vãos, sendo que em cada vão, há quatro longarinas metálicas, ligadas entre si pela laje superior. As lajes, os pilares e as travessas da ponte são estruturados em concreto armado, sendo que a pista de rolamento possui duas faixas com folgas e guardarodas em ambos os lados. A mesoestrutura é formada por pórticos com pilares de concreto armado ligados por travessas em seus topos que apoiam diretamente a superestrutura.

Para identificação das tais manifestações existentes na ponte foi realizada uma inspeção visual (outubro de 2018). A inspeção foi realizada analisando os possíveis pontos críticos como, por exemplo, os apoios, juntas, guarda-corpo e pavimentação. 
SANTOS, C. G. DOS; BENETTI, H. P.; DIAS, G. L.. TÉCNICAS PARA RECUPERAÇÃO DE PONTE DE CONCRETO ARMADO: ESTUDO DE CASO. $4^{\circ}$ Simpósio Paranaense de Patologia das Construções (40 SPPC), artigo 4SPPC112, pp. 91 - 100, 2019. DOI: $10.4322 / 2526-7248.032$

A análise dos mecanismos de degradação, existentes, foi realizada apenas na superestrutura e na mesoestrutura, uma vez que não foi possível o acesso às fundações. A vistoria foi executada levando em consideração o prazo e instrumentos disponíveis.

\subsection{Mecanismo de degradação identificadas na Superestrutura}

A falta da junta de dilatação junto ao pórtico, e as fissuras provocadas atuam como local de infiltração da água da chuva, o que ocasionou um degrau na pista, na transição entre a rodovia e a ponte.

Analisando as áreas de apoio da laje com as vigas longarinas, observou-se a ocorrência de fissuras na laje, fazendo com que as armaduras fiquem vulneráveis a agentes agressivos, ocasionando sua despassivação (ação responsável pelo fenômeno da corrosão das armaduras).

Em alguns pontos da laje, foi possível observar a ocorrência de infiltração de água e a ocorrência do fenômeno da lixiviação, identificado pela existência de manchas brancas ao longo da laje no local observado, fazendo com que haja diminuição da capacidade resistente do concreto, além de permitir a corrosão das armaduras.

Ao analisar os drenos existentes na laje foi observado que devido às dimensões insuficientes, a água que passa por ele escorre pela parte inferior da laje e infiltra no pilar, ocorrendo em quatro apoios da estrutura. A presença da água sob a laje e nos pilares pode fazer com que haja o desplacamento da laje naquele local, e também causar danos à estrutura metálica.

Em alguns pontos houve o desplacamento do concreto e armaduras expostas na laje, devido à infiltração de agentes agressivos no concreto, e a exposição de algumas armaduras a esses agentes, sofrendo corrosão e expansão, causando tensões no concreto e rompendo os elementos.

As vigas metálicas estão em bom estado de conservação, porém foi observada a ausência de parafusos em uma transversina metálica, e foi reportado uma falta das travessas de enrijecimento das treliças. Os danos que a falta desse elemento pode causar à estrutura é permitir com que haja maiores deformações na estrutura devido ao carregamento e ações do vento.

\subsection{Mecanismo de Degradação identificadas na Mesoestrutura}

Em virtude da presença de água na laje de concreto, pela falha nas juntas de dilatação apresentadas anteriormente e pela percolação dessa água nos elementos de concreto abaixo da laje, foi possível observar a ocorrência de desplacamento do concreto no encontro com a longarina metálica.

Alguns aparelhos de apoio metálicos apresentaram incidência de corrosão, entretanto, o tipo de corrosão observado nestes elementos é de fácil recuperação, pois consiste em uma camada de óxido de ferro pouco aderente formada em toda a extensão da peça. Esse defeito ocorre devido à exposição dos elementos metálicos à umidade sem um sistema de proteção, e pode causar diminuição da seção transversal da peça [12]. 
SANTOS, C. G. DOS; BENETTI, H. P.; DIAS, G. L.. TÉCNICAS PARA RECUPERAÇÃO DE PONTE DE CONCRETO ARMADO: ESTUDO DE CASO. $4^{\circ}$ Simpósio Paranaense de Patologia das Construções (40 SPPC), artigo 4SPPC112, pp. 91 - 100, 2019. DOI: $10.4322 / 2526-7248.032$

No aparelho de apoio fixo, verifica-se que o processo de corrosão está mais avançado, e que algumas partes do apoio já estão se deteriorando, o que indica perda da seção transversal. No aparelho de apoio móvel, o processo de corrosão ainda está na fase inicial, não apresentando perdas na seção.

\subsection{Recuperação da estrutura}

Após a identificação e classificação das manifestações patológicas existentes foi elaborado um plano de recuperação da estrutura. Na ponte sobre o Rio Xagú serão abordadas apenas as questões pertinentes à recuperação de cada tipo de mecanismo de degradação.

Para a superestrutura foram identificadas técnicas para recuperação das manifestações como a falta ou inoperância de juntas de dilatação, fissuras na laje, percolação de água na laje, drenos insuficientes na laje e danos nos elementos metálicos da superestrutura.

A melhor solução para a falta ou inoperância de juntas de dilatação é a construção de juntas fechadas elastoméricas de compressão. Esta junta consiste em um bloco retangular de neoprene com aberturas alveolares e deve ser protegido por cantoneiras de aço. O bloco de neoprene trabalha sempre com efeitos dos esforços de compressão, e as aberturas permitem que ele possa acompanhar os movimentos de expansão e contração da ponte.

O tratamento para a vedação, de fissuras ativas na laje, se dá pela aplicação de selante, seja ele a base de betume ou poliuretanos. Após a aplicação do selante, as fissuras podem ser reparadas por injeção de resina epóxi, devido à sua pequena abertura.

Nesta laje em estudo, as fissuras tem origem pela infiltração de água e agentes nocivos, e a consequente corrosão da armadura, além da solicitação do elemento estrutural devido às cargas de tráfego. Portanto, foi necessário verificar o estado das barras de aço, para a realização do tratamento para remoção de corrosão, antes de iniciar o tratamento das fissuras.

A percolação de água pela laje fez com que ocorresse a lixiviação do concreto e, consequentemente, sua carbonização. Estes acontecimentos permitem a entrada de cloretos do ambiente no concreto, permitindo a corrosão das armaduras. Segundo o manual do DNIT [6], existem alguns processos, na tentativa de transformar os compostos nocivos do ambiente, para que ao penetrar nos poros do concreto não causem a despassivação da armadura, tais como: tratamento com água, com leite de cal ou eletrosmose. Entretanto, o único processo com eficácia comprovada é a remoção da camada de concreto contaminada.

Quanto aos drenos, estes devem ser substituídos por outros de tamanho adequado e implantar pingadeiras para que a água não escorra pela laje. Em seguida, deve ser verificado se a água causou algum dano à estrutura metálica ou desplacamento no pilar, para então aplicar as técnicas de recuperação para cada uma dessas degradações. 
SANTOS, C. G. DOS; BENETTI, H. P.; DIAS, G. L.. TÉCNICAS PARA RECUPERAÇÃO DE PONTE DE CONCRETO ARMADO: ESTUDO DE CASO. $4^{\circ}$ Simpósio Paranaense de Patologia das Construções (4º SPPC), artigo 4SPPC112, pp. 91 - 100, 2019. DOI: $10.4322 / 2526-7248.032$

O primeiro procedimento na recuperação do desplacamento do concreto é a remoção da corrosão das armaduras. Contudo, para que se tenha acesso a toda a área danificada das armaduras, deve-se escorar a área a ser recuperada e realizar a escarificação do concreto (exposição de agregados) neste local. A remoção da corrosão das armaduras pode ser feita com escovas de aço, lixas (manuais ou mecânicas) ou jatos de areia. Caso a área da seção tiver diminuído mais do que $10 \%$, será necessária a colocação de mais barras de aço como reforço estrutural e uma proteção contra corrosão deve ser aplicada nas armaduras já tratadas [13].

Para a mesoestrutura foram identificados o desplacamento do concreto no encontro com a longarina metálica, onde deve ser feita a limpeza em ambas as partes com a utilização de epóxi primer anticorrosivo de zinco e aplicação de duas camadas de revestimento com pintura epóxi de alta dureza, além de lubrificar a articulação móvel utilizando graxa a base de silicone.

Após apresentar as manifestações patológicas relatadas na ponte em estudo e identificar as técnicas de recuperação, foi elaborada a Fig. 4, a qual identifica a manifestação, a técnica de recuperação e o registro da situação atual.

\begin{tabular}{|c|c|c|}
\hline $\begin{array}{l}\text { Manifestação } \\
\text { Patológica }\end{array}$ & Técnica de Recuperação & Registro \\
\hline $\begin{array}{l}\text { Falta ou } \\
\text { inoperância das } \\
\text { juntas de } \\
\text { dilatação }\end{array}$ & $\begin{array}{c}\text { Construção de juntas de } \\
\text { elastômeros de } \\
\text { compressão com bloco } \\
\text { neoprene. }\end{array}$ & \\
\hline $\begin{array}{c}\text { Fissuras ativas } \\
\text { na laje }\end{array}$ & $\begin{array}{l}\text { Vedação da fissura com } \\
\text { selante, injeção de resina } \\
\text { epóxi. }\end{array}$ & \\
\hline $\begin{array}{l}\text { Percolação de } \\
\text { água na laje e } \\
\text { consequente } \\
\text { lixiviação }\end{array}$ & $\begin{array}{l}\text { Remoção da camada de } \\
\text { concreto contaminada. }\end{array}$ & \\
\hline $\begin{array}{l}\text { Drenos com } \\
\text { tamanho } \\
\text { insuficiente }\end{array}$ & $\begin{array}{l}\text { Substituição dos drenos e } \\
\text { implantação de } \\
\text { pingadeiras. }\end{array}$ & \\
\hline $\begin{array}{l}\text { Desplacamento } \\
\text { do concreto e } \\
\text { armaduras } \\
\text { expostas } \\
\text { (setas) }\end{array}$ & $\begin{array}{c}\text { Escarificação do concreto, } \\
\text { remoção da corrosão das } \\
\text { armaduras, possivel reforço } \\
\text { estrutural das armaduras, } \\
\text { colocação de adesivo de } \\
\text { resina epóxi e lançamento } \\
\text { da nova camada de } \\
\text { concreto. }\end{array}$ & \\
\hline $\begin{array}{l}\text { Elementos } \\
\text { faltantes da } \\
\text { estrutura } \\
\text { metálica }\end{array}$ & $\begin{array}{l}\text { Reposição dos parafusos } \\
\text { nas transversinas e das } \\
\text { travessas de enrijecimento. }\end{array}$ & \\
\hline $\begin{array}{l}\text { Corrosão nos } \\
\text { elementos } \\
\text { metálicos }\end{array}$ & $\begin{array}{l}\text { Limpeza com epóxi primer } \\
\text { anticorrosivo de zinco e } \\
\text { aplicação de duas camadas } \\
\text { de revestimento com } \\
\text { pintura epóxi de alta } \\
\text { dureza. Lubrificação das } \\
\text { articulações móveis com } \\
\text { graxa a base de silicone. }\end{array}$ & \\
\hline
\end{tabular}

Figura 2: Manifestações patológicas, técnicas para a recuperação e registro. Fonte: os autores. 
SANTOS, C. G. DOS; BENETTI, H. P.; DIAS, G. L.. TÉCNICAS PARA RECUPERAÇÃO DE PONTE DE CONCRETO ARMADO: ESTUDO DE CASO. $4^{\circ}$ Simpósio Paranaense de Patologia das Construções (40 SPPC), artigo 4SPPC112, pp. 91 - 100, 2019. DOI: $10.4322 / 2526-7248.032$

\section{Conclusões}

Identificar as manifestações patológicas presentes em uma estrutura e compreender os mecanismos de degradação que as originaram, mostra a importância da utilização das normas como embasamento para execução de obras, pois quando uma obra é construída levando em consideração os aspectos descritos nas normas, a vida útil da estrutura é aumentada significativamente.

As manifestações não ocorrem de maneira isolada, logo, um defeito pode levar a diversos outros, como aconteceu na ponte sobre o Rio Xagú. Muitas destas surgem pela falta de acompanhamento e manutenção periódica da estrutura. É importante perceber que um projeto de recuperação não deve ser realizado apenas quando a estrutura já está comprometida, e sim haver um planejamento periódico de manutenção.

Por fim, a partir do levantamento das manifestações patológicas na referida ponte, pode-se concluir que mesmo apresentando defeitos recorrentes em estruturas de concreto armado, a ponte ainda encontra-se em bom estado. Mesmo sendo necessário realizar a manutenção da estrutura, os defeitos apresentados ainda podem ser considerados pontuais, não afetando a estrutura como um todo.

\section{Referências}

[1] Souza, v. c.; Ripper, T. (1998) Patologia, recuperação e reforço de estruturas de concreto. São Paulo: Pini, 255 pg.

[2] FRANÇA, Alessandra A. V.; MARCONDES, Carlos Gustavo N.; ROCHA, Francielle C. da; MEDEIROS, Marcelo Henrique Farias de; HELENE, Paulo R. L. Patologia das construções: uma especialidade na engenharia civil. Téchne, São Paulo, v. 19, n. 174, p. 72-77, 2011.

[3] Santos, R. E. dos. (2006) A cultura do concreto armado no Brasil: educação e deseducação dos produtores do espaço construído. In: Anais do IV Congresso Brasileiro de História da Educação. Goiânia: Universidade Católica de Goiânia, 2006.

[4] Medeiros, H. (2010) Doenças concretas. Téchne. 160 ed.

[5] Helene, Paulo R. L. (1992) Manual para Reparo, Reforço e Proteção de Estruturas de concreto. 2 ed. São Paulo: Pini.

[6] Brasil. Ministério dos Transportes. DNIT (2010) - Departamento Nacional de Infraestrutura de Transportes. Manual de Recuperação de Pontes e Viadutos Rodoviárias. IPR Pub. 744. Rio de Janeiro, 2010, 161 p.

[7] Pita, M. (2011) Porque impermeabilizar pontes e viadutos. Infraestrutura urbana: projetos, custos e construção. 14 ed.

[8] Muller, R. (2004) Critérios para o planejamento e execução de recuperações estruturais em pontes e viadutos rodoviários no Estado do Paraná. Dissertação (mestrado), Universidade Federal do Paraná, Curitiba, Brasil. 
[9] Cichinelli, G. (2014) Recuperação e reforço de pavimentos. Infraestrutura urbana: projetos, custos e construção. 37 ed.

[10] Ferreira, R. (2014) Inspeção e reforço estrutural de pontes. Infraestrutura urbana: projetos, custos e construção. 40 ed.

[11] Mitre, M. P. (2005) Metodologia para inspeção e diagnóstico de pontes e viadutos de concreto. Dissertação (mestrado). Escola Politécnica da Universidade de São Paulo, São Paulo, Brasil.

[12] BRASIL. Ministério dos Transportes. DNIT (2015) - Elaboração de projeto básico e executivo - Projeto de engenharia para recuperação, reforço e reabilitação de Obras de Arte Especiais da Rodovia BR-158/PR. Porto Alegre.

[13] Sachs, A. (2015) Tratamento intensivo. Téchne. 220 ed. p. 40-44, São Paulo, Brasil. 